\title{
Level of Knowledge of Sustainable Development (SD) in the Master's Program Sustainable Building Information Management (BIM)
}

\author{
Annika K. Jägerbrand ${ }^{1, *}$ \\ 1 Department of Construction Engineering and Lighting Science, School of Engineering, \\ Jönköping University, P.O. Box 1026, SE-551 11 Jönköping, Sweden, Email: \\ annika.jagerbrand@ju.se
}

Corresponding Author: *Correspondence: annika.jagerbrand@ju.se; Tel.: + 46 36-10 1696

\begin{abstract}
Sustainable development (SD) is essential to reduce and mitigate climate change impacts, environmental deterioration and to increase social sustainability. SD is therefore highly relevant for the engineering profession and is today found integrated with the higher education of specific engineering programs. This paper investigated the knowledge of SD for students entering the master's program in Sustainable Building Information Management (BIM) by comparing levels of knowledge at the start and end of the first course Sustainability, Analyses and Simulations.
\end{abstract}

The level of knowledge of SD was analyzed by classifying students' conceptions of sustainability using SOLO taxonomy and the spectrum of liminality and the threshold concept. Students written responses to the question "What do you know about sustainability?" and written group project reports were used for analyzing levels of knowledge of SD. Levels of knowledge of SD was classified as pre (pre-liminal or pre-structural); uni-structural, multistructural, relational and post-stages (extended abstract or post-liminal).

In total, $68 \%$ of the students entering the master's program in 2017 and $88 \%$ in 2018 showed a pre-structural, uni-structural and multi-structural SD knowledge. In general, few students entering the program showed relational and post-stages of SD knowledge, $32 \%$ and $12 \%$ of the students in 2017 and 2018, respectively. The students at the post-stage were able to express themselves more individually and creatively compared to previous levels in that they could connect the dimensions of SD to the context of SD of buildings, but also argue why SD of buildings was important and they could also suggest actions or tools for improved SD that engineers should use.

Only one group of five (in 2017) showed a post-stage level of knowledge in the group project report. It is likely that the student's general approach to the work with the reports was to mainly cope with the course requirements which is a sign of surface approach to learning. It, therefore, seems reasonable that future developments of the course should ensure that the students use the scientific literature in their group project reports to make it easier for them to understand the relationship between software use and the connection to green buildings certificate systems and SD of buildings. By making it mandatory to include scientific literature in the reports the students will be encouraged to read and think critically, and deeper, and to put the practical implementation of the software analysis results into a scientific context of $\mathrm{SD}$ and BIM.

Keywords: BIM; SOLO; threshold concepts; green buildings; certificate systems; higher education 


\section{Level of Knowledge of Sustainable Development in Sustainable Building Information Management}

\section{Introduction}

Demand for sustainable buildings that have low climate change and environmental impact is increasing since the building industry is responsible for consumption of a large proportion of global resources, wood products, raw materials and results in waste products, and emissions of greenhouse gases (see, for example, Marjaba \& Chidiac, 2016; Oduyemi \& Okoroh, 2016; Suzer, 2015).

The concept of sustainability is commonly thought to originate from the report "Our Common Future" (Brundtland, 1987) which defined sustainable development (SD) as:

"Sustainable development is development that meets the needs of the present without compromising the ability of future generations to meet their own needs"

Dimensions of sustainability for buildings usually includes environmental, economic and social aspects (Jrade \& Jalaei, 2013), but may also include procedural aspects (for example Marjaba \& Chidiac, 2016). Social aspects are also referred to as social well-being and includes, for example, the indoor environmental quality such as daylight and noise conditions. Evaluation of the sustainability of construction projects is usually performed by the use of green rating systems or certificates (Guldager Jensen \& Birgisdottir, 2018). However, many green rating systems fail to address all of the relevant sustainability aspects or indicators (Marjaba \& Chidiac, 2016). For example, in a comparison of four different green building rating systems, only one system could assess all the sustainable factors investigated (Doan et al., 2017). In addition, the accomplishment of a green building certification does not necessarily mean that the building succeeded in achieving its environmental targets (Awadh, 2017). Hence, since SD of buildings is not fully covered by green certificate systems and can vary with the systems used, it might be challenging for students to fully understand how SD of buildings is achieved.

Building information modelling (BIM) can be used for assessments of the building's sustainability in the planning and design stage (Chong, Lee, \& Wang, 2017; Lu, Wu, Chang, \& Li, 2017; Maltese et al., 2017; Wong \& Zhou, 2015). In practical application, several software is used that analyze and yield data on different aspects of sustainability, for example, energy consumption, costs, Life Cycle Analysis (LCA), $\mathrm{CO}_{2}$, and daylighting. A life cycle perspective of the building must be adopted for a correct assessment and include the building planning and design, construction process, building operation, building repair and management and building demolition (Wong \& Zhou, 2015). Consequently, to fully understand how buildings may achieve a higher degree of SD by BIM it is necessary to understand the dimensions of sustainability in the construction and use of buildings, which aspects are included in the software and to fully consider buildings from a life cycle perspective.

A previous study on what engineering students learn in sustainability courses reveals that students perceive sustainability as mainly related to technology with little relevance in the social and attitudinal aspects (Segalàs, Ferrer-Balas, \& Mulder, 2010). How much engineering students know about sustainable development was investigated in an international survey in 2005 (Azapagic, Perdan, \& Shallcross, 2005). The results show that most students claimed to have some knowledge or know a lot about several specific environmental problems (for example global warming and deforestation) but they showed knowledge gaps regarding the components of SD, approaches to SD, and inter- and intra-generational equity. The study also showed that the difference in knowledge between year 1 and year 5 in the education was only 3\% (Azapagic et al., 2005). Such small differences in knowledge of SD between several years 


\section{Level of Knowledge of Sustainable Development in Sustainable Building Information Management}

of engineering studies suggest that SD is either not included or adequately integrated in the overall curriculum in the education.

At the School of Engineering at University of Jönköping a master's program in sustainable building information management started in 2017 and the program has integrated SD in the program syllabus. Common learning outcomes regarding leadership, project management, internationalization and sustainable development is also included in the concept of the program. Eligibility for students to enter the master's program is a bachelor's degree (equivalent of 180 ECTS credits, i.e. European Credit Transfer and Accumulation System) with at least 90 ECTS credits in construction engineering or civil engineering or equivalent, and 15 ECTS credits in mathematics. The master's program is situated in the second cycle of the higher education qualifications, while the bachelor's degree which is needed for eligibility is within the first cycle (typically 180-240 ECTS credits) and follows the Bologna process (Bologna Working Group on Qualifications Framework, 2005). After completion of the master's program (90-120 ECTS credits), students are eligible for entering the third cycle (doctoral degree) of higher-education qualifications (Bologna Working Group on Qualifications Framework, 2005).

Hitherto, no evaluation of student's knowledge of SD in the program has been performed. Evaluations can be performed by using, for example using Bloom's and Krathwohl taxonomies categories to evaluate educations between universities (Segalàs, Ferrer-Balas, Svanström, Lundqvist, \& Mulder, 2009), or with questionnaires to students regarding their knowledge of SD (Azapagic et al., 2005) or by comparing students written responses using a modified version of the Structure of Observed Learning Outcomes (SOLO) taxonomy (Carew $\&$ Mitchell, 2002). However, students' knowledge can also be analyzed by threshold concept and capabilities (Baillie, Bowden, \& Meyer, 2013; Meyer \& Land, 2003).

The overall aim of this research project was to investigate the level of knowledge of SD for students entering the master program in sustainable building information management at the School of Engineering.

More specifically, the following questions were investigated:

I. Most students should have at least some basic knowledge of SD when entering the program, but the level of knowledge is situated in the early phases (threshold concept) or lower levels of Bloom's taxonomy or SOLO taxonomy.

II. At the end of the first course in the first semester, the students' knowledge of $\mathrm{SD}$ in connection to BIM and buildings should have increased compared with entering the program.

This paper investigated the knowledge of SD for students starting at the master's program by comparing levels of knowledge at the start and end of the first course "sustainability, analyses and simulations". Students written responses to the question "What do you know about sustainability" when entering the Sustainable Building Information Management Program was analyzed in 2017 and 2018. Students written project reports after finishing the course sustainability, analyses and simulations in 2017 was analyzed. The level of knowledge of SD was analyzed by classifying students' conceptions of sustainability using SOLO taxonomy, and the spectrum of liminality, and the threshold concept. Since the master's program is international, the students have taken their bachelor's degree around the world. This was also taken into consideration by classifying students that had a higher education in European and non-European countries. 


\section{Level of Knowledge of Sustainable Development in Sustainable Building Information Management}

\section{Methodology and method}

\subsection{Theoretical Framework for Classifying the Understanding of Sustainability}

This study created a new theoretical framework for classifying the understanding of sustainability by combining the SOLO-based taxonomy for engineering students understanding of sustainability by Carew \& Mitchell (2002), with the spectrum of liminality which was developed for engineering students studying social justice (Kabo \& Baillie, 2009).

The SOLO-based taxonomy by Carew \& Mitchell was developed from a perspective of an expert-like understanding of sustainability, taking the knowledge of content and structure into consideration, and adapting the SOLO taxonomy to sustainability knowledge (Carew \& Mitchell, 2002). When creating the new theoretical framework, levels of understanding and the detailed description of SOLO levels in approaches to learning questions and why was also used (Biggs \& Tang, 2011).

The threshold concept is explained in greater detail by Meyer \& Land (Meyer \& Land, 2003):

"A threshold concept can be considered as akin to a portal, opening up a new and previously inaccessible way of thinking about something. It represents a transformed way of understanding, or interpreting, or viewing something without which the learner cannot progress. As a consequence of comprehending a threshold concept there may thus be a transformed internal view of subject matter, subject landscape, or even world view. This transformation may be sudden or it may be protracted over a considerable period of time, with the transition to understanding proving troublesome. Such a transformed view or landscape may represent how people 'think' in a particular discipline, or how they perceive, apprehend, or experience particular phenomena within that discipline (or more generally)."

Students can be seen as navigating along a spectrum of liminality (Kabo \& Baillie, 2009). The spectrum of liminality is described as five positions of knowledge/understanding stages, developed from the concepts of phenomenography and thresholds.

The new theoretical framework presents a combined system of classifying students' conceptions of sustainability using SOLO taxonomy and spectrum of liminality and threshold, adapted from (Carew \& Mitchell, 2002; Kabo \& Baillie, 2009) and is described below.

Position A is classified as the pre-liminal stage and is like the pre-structural stage in the SOLO taxonomy (Figure 1). Also position B in entering the liminal stage is similar to SOLO stage uni-structural in, for example, being one-directional or focused on one example. For sustainability, this stage represents the ability to mention random aspects and to use fragments such as the definition of sustainable development according to the Brundtland report.

In social justice, position $\mathrm{C}$ reflects aspects such as charity and duty and telling people what do to. The stage demonstrates an increased knowledge in content and theoretical aspects but there seems to be a lack of structural knowledge. The position $C$ in the spectrum of liminality cannot be directly compared with multi-structural conceptions as is the next stage in the SOLO stage. 


\section{Level of Knowledge of Sustainable Development in Sustainable Building Information Management}

Multi-structural knowledge reflects an ability to give examples of two or more aspects that are considered important for sustainable development. However, it is when students are able to combine concepts and can create statements and arguments for sustainable development that they are entering the relational stage. The relational stage can be compared to position $\mathrm{D}$ in the spectrum of liminality, although they differ since the SOLO stages are more focused on the SOLO taxonomy and the spectrum of liminality and threshold is more focused on social justice (e.g. action for change, being respons-able).

The post-stage of student's conceptions of sustainability demonstrates clear similarities between the SOLO stages and the spectrum of liminality (Figure 1). The students in the poststages have left the liminal space and reached the threshold, being able to make critical analysis in social justice, making social justice a lens for looking at the world. Similarly, when students enter the post-stage of extended abstracts, they are able to provide evidence of criticality, ethics, contextuality and creative thinking around sustainable development.

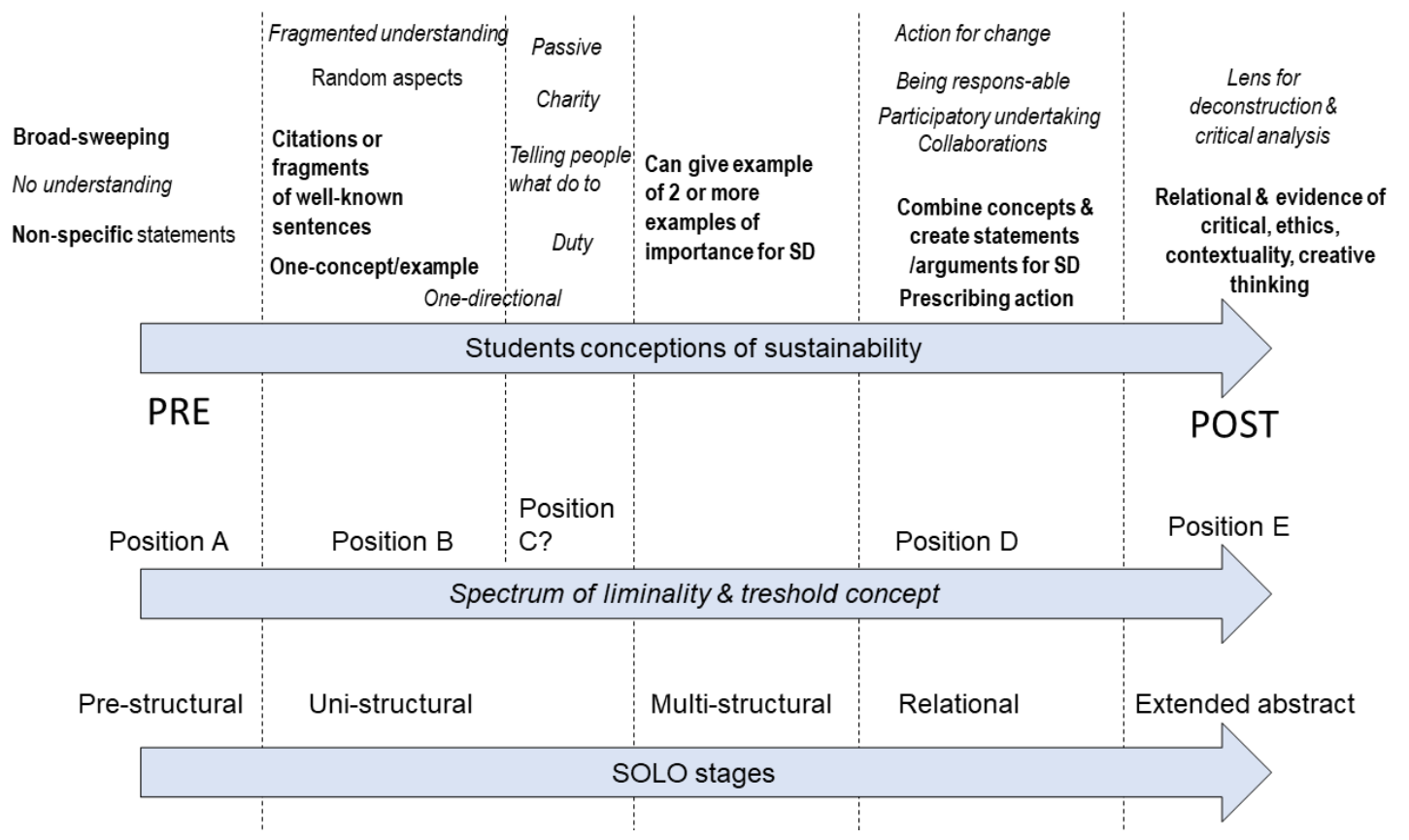

Figure 1. A combined system of classifying students' conceptions of sustainability using SOLO taxonomy and spectrum of liminality and thresholds, adapted from Carew \& Mitchell (2002), and Kabo \& Baillie (2009). "PRE": pre-liminal or pre-structural. Italics: Conceptions along spectrum of liminality developed for social justice. Bold: sustainability concepts derived from using SOLO taxonomy and SOLO stages.

\subsection{Method}

The master's program Sustainable Building Information Management started at the School of Engineering at Jönköping University in 2017. The program leads to a master's in science (120 ECTS credits, two years) with a major in product development. The master program is international, lectures are given in English, and there are a high proportion of students from non-European countries, for example, Africa, Middle East and East Asia.

The course Sustainability, Analyses and Simulations is one of two initial parallel courses in the program. The intended learning outcomes for the Sustainability, Analyses and Simulation course is focused on an understanding of the concept of sustainability, BIM, sustainability 


\section{Level of Knowledge of Sustainable Development in Sustainable Building Information Management}

assessment systems and skills to build BIM models, perform analyses and simulations to assess sustainable project performance qualities. One intended learning outcome in judgement and approach states that after a successful course, "students shall...demonstrate the ability to identify, analyse, simulate and evaluate vital building performance criteria from a sustainability aspect". The course is given as lectures, exercises, and project work.

At the very start of the course students are requested to make both an oral (maximum 5 min) and a written presentation (maximum 5 slides in power point) where they describe themselves, their education, and what they know about BIM and sustainability, respectively. More specifically, they are asked to answer the question: "What do you know about sustainability?".

During the course they will read scientific literature within the area (BIM, sustainability and buildings certificate systems) and conduct simulation analyses in BIM and in software programs for daylight analyses and energy analyses for a building. The students used Autodesk Revit - Insight 360 (in Autodesk package), and IDA Ice for analyses of daylight and energy. Energy analysis mainly covered cooling and heating. The environmental building certificates used for evaluating the sustainability of their buildings in 2017 were miljöbyggnad, LEED ${ }^{\text {TM }}$ Green Building Rating System, BREEAM (BRE Environmental Assessment Method) and DGNB (German Sustainable Building Council).

At the end of the course, a mandatory assignment is to write a group project report with detailed descriptions of software analysis and the results, together with a description on how they managed with the green certificate systems of the SD of the buildings (more specifically regarding daylight analysis and energy).

The student's own descriptions of their knowledge at the beginning of the course was investigated by analyzing the written descriptions on what they know about sustainability with their own words. Only students that passed were included. The students written group project reports was evaluated, but only from the perspective if they had reached the post-stage or not (i.e. crossed the threshold). Group project reports from 2017 was analyzed.

\section{Results and Discussion}

\subsection{Level of SD Knowledge at the Course Start}

At the start of the course, when entering the master's program, students showed various knowledge levels of sustainable development (Figure 2). There was a trend of increased level of pre-existing knowledge of SD for students with European education compared with students with education from non-European countries (Figure 2). The study by Azapagic et al. (2005) showed that there was no difference in students knowledge of SD between developed and developing countries, but that students from some specific countries seemed to possess higher SD knowledge (for example Sweden, Germany and Vietnam). 


\section{Level of Knowledge of Sustainable Development in Sustainable Building Information Management}

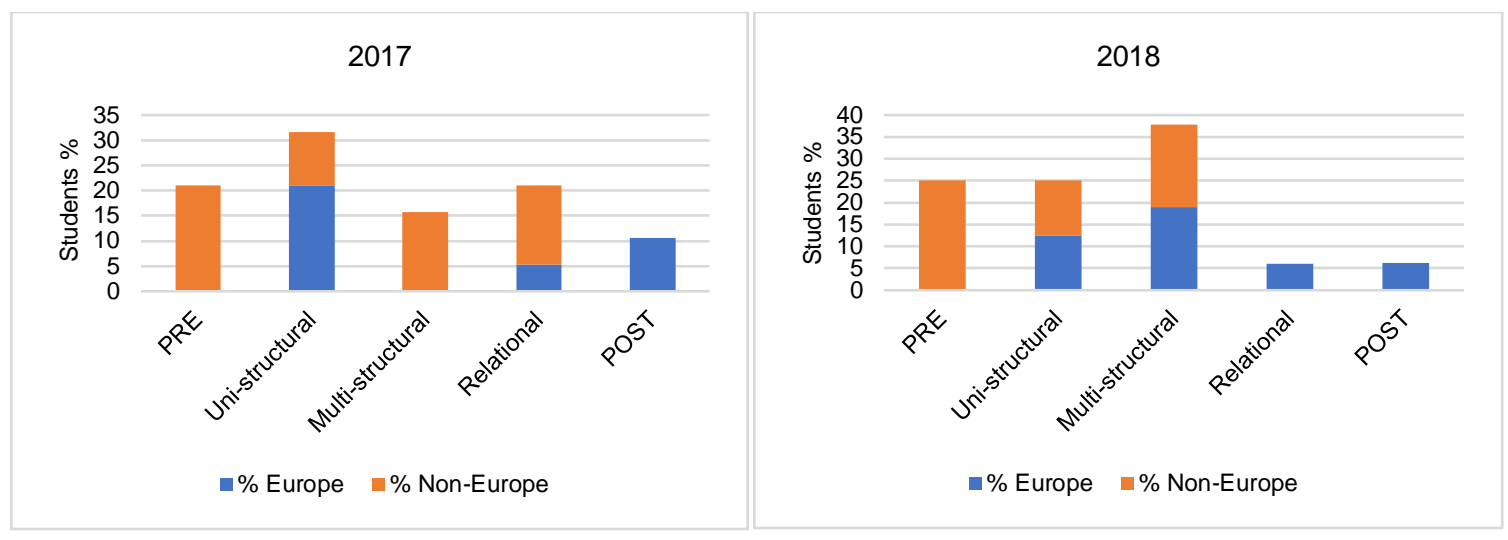

Figure 2. Stages of knowledge of Sustainable Development (SD) at start of the course in 2017 and 2018. Number of students $n=19$ in 2017, and $n=16$ in 2018.

Approximately one fourth of the students (21\% in 2017 and 25\% in 2018) showed prestructural knowledge at the start of the course. Pre-structural knowledge was exhibited by no understanding of sustainability as a concept (three dimensions), but guessing or non-specific statements. For example, students referred to a fact they thought was important, such as maintaining or withstanding a level or rate for comfort, structures or in general (but unspecified regarding what and how and the connection to sustainability). Another group of students seemed to express some uncertainty of what SD is in an academic context but were able to make broad-sweeping argumentation about the ecological-environmental importance, such as "property of biological systems" or environmental actions undertaken in the society (for example planting trees) or "... make the world a better place..".

All students at the pre-structural stage had taken their previous education in non-European countries. Several of the students from the European countries had previously taken courses at Jönköping University where SD is included in the education and therefore already had higher levels of knowledge of SD.

In total, $68 \%$ of the students in 2017 and $88 \%$ in 2018 showed a pre-structural, uni-structural and multi-structural knowledge (Figure 2). Of these, uni-structural and multi-structural knowledge was shown by almost half of the students (47\% in 2017 and $62 \%$ in 2018). The uni-structural answers were, for example, quoting the Brundtland report or modifications of the Brundtland definition where the functioning of the definition was more or less obvious, for example, "Working towards a society that is durable and lasting for generations to come". The students knew some of the terminology used for SD. Students were also referring to the three pillars of sustainability in a general way, stating, for example, "Environment, Economic, Social". These statements were not always connected to the engineering field or buildings/architecture.

For the uni-structural and multi-structural knowledge, the percentages of students with education from Europe and from non-European countries were more equal, except for the multi-structural level in 2017 (only non-European).

For multi-structural levels of knowledge, some of the students expressed both a general definition of SD and two or more aspect that are important for the sustainability of buildings, for example, resource efficiency, energy efficiency/conservation or life cycle perspectives. Another group of students mentioned several aspects of importance for the sustainability of buildings. These aspects could be both direct or indirect, for example, "cost efficiency" and "impact on human beings". The explanations were often stating facts and therefore had a more 


\section{Level of Knowledge of Sustainable Development in Sustainable Building Information Management}

declarative character, for example "long service life", "saving energy", "recycling" "waste management", "meeting the needs of residents" or mentioning green building certificate systems. This group also contained students that had professionally worked with environmental or SD questions practically before entering the master program, or that had taken courses that included sustainability or green building certificates systems at the bachelor level.

In general, few students showed relational and post-stages of knowledge, $32 \%$ and $12 \%$ of the students in 2017 and 2018, respectively (Figure 2). The relational level of knowledge shows an ability to combine concepts and prescribing actions, for example, "creating structures that are environmentally friendly.... by creating a long life-circle buildings" and "..to construct and utilize building in the most energy efficient way and to be environmentally friendly... after its demolition the waste materials should be recycled".

Knowledge at the level of post-stages shows an analytical knowledge of activities of SD and a view of being able to perform critical analysis.

For example, one student:

- defined the three dimensions of SD

- examined the aspect of renewable resources

- defined what a reduction of resources is within the context of buildings as "goal"

- presented five examples of reduced waste management

- presented how resource efficiency can be achieved by three actions when working with buildings and their design

Another student also defined SD, both general terms and in the context of building design (several aspects and functions), and showed argument that SD of buildings is important for many aspects for human well-being and refers to using assessment tools and to "always have a sustainable perspective when working with buildings and develop cities".

The students at the post-stage were able to express themselves more individually and creatively compared to previous levels in that they could connect the dimensions of SD to the context of SD buildings, argue why it was important and suggest actions or tools for improved SD that engineers should use. Compared with social justice, few students expressed a clear view of who should do the actions although one student at the post-stage level states that "sustainability is about...the environment and how we can protect it", showing that protecting the environment is something that "we" do. Although unclear whether "we" means the society in general or engineers in the education, it shows that the students think of sustainability as being response-able (suggesting actions and ways to work with it in building designs).

Only (three) students with an educational background within Europe were at the post-stages. This could be due to less experience and knowledge in SD of buildings for students with educations from non-European countries, but this could also be due to barriers in language, education or culture for the students. It is not certain that all students are comfortable in presentations in English, written and orally, which could lead to lower performance.

\subsection{Level of Knowledge of SD in Group Project Reports}

Only one group of five (in 2017) showed a post-stage level of knowledge. In the report, the findings from the software analyses were discussed from the perspective of the SD dimensions and how the aspects of improved daylight conditions and energy efficiency covered different 


\section{Level of Knowledge of Sustainable Development in Sustainable Building Information Management}

SD dimensions. The text was written by one of the group members (each text section throughout the report had the authors name clearly shown). For the daylight aspects, the discussion also covered various technical ways to improve daylight conditions (for example "transmittance, reflectance, orientation, solar shading") and that these aspects increase social sustainability in terms of a good indoor environment, but also how daylight conditions affects the need for heating and cooling. This shows a high level of functioning knowledge (in accordance with SOLO stages) and deep or strategic approach to learning (Entwistle, 2005). Moreover, the report states that energy is connected to the economic and environmental dimensions and makes connections to the social dimensions by referring to an "...understanding of the human dimension and how human is interacting with buildings" to better understand energy use in buildings. The discussion includes references of several scientific peer-reviewed papers of relevance for the topic. Surprisingly, none of the students in the group showed higher stages of knowledge at the start of the course (pre-structural and uni-structural knowledge).

The other groups showed that they managed to use the software, although some had difficulties with producing results due to conflicts and various technical problems. Typically, the groups did manage to cover facts and more direct effects of, for example, daylight conditions of buildings (that they could change), and the groups also made some statements on energy use of the building, but they did not connect these aspects to the green building certificate, to SD or to which dimensions they were actually working on improving when using the software. The need for inter-operational among BIM software and energy simulation tools has been identified previously by Chong et al. (2017). In the same paper, the authors also identified the need for new BIM tools to assess sustainability criteria better. This is also clearly shown by the group project reports.

It seems that the students are very focused on the task at hand (i.e. the software analyses and factual knowledge), and less focus is directed towards understanding the functioning of SD and/or the building certificate systems as a wholeness. Surprisingly, the groups that included students that showed a post-stage knowledge of SD when starting the course did not exhibit a group-level post-stage knowledge.

It is likely that the student's general approach to the work with project reports was to cope with the course requirements and the intentions was not entirely to understand the ideas, which is typically described for surface approaches to learning (Biggs \& Tang, 2011; Entwistle, 2005). In this specific examined activity, the instructions did not explicitly state that the project reports must contain scientific references. Hence, the students managed to treat the knowledge gained from the software analyses as unrelated bits of knowledge, which is also typical of a more surficial approach to learning (Entwistle, 2005). Surface approaches to learning will not lead to higher levels of knowledge but make the students stay in uni-structural or multi-structural knowledge stages.

The scientific papers on SD and building certificates was intended to make it clearer for the students in which theoretical framework and context the results from the software analysis should be placed. This would also aim towards enhancing a deep learning of the subject in accordance with the intended learning outcomes. Consequently, it seems reasonable that future developments of the course should ensure that the students use the scientific literature in their reports to make it easier to understand the relationship between software use and adaptations and the connection to environmental certificate systems and SD. By making it mandatory to include scientific literature in the reports, the students will be encouraged to read and think critically about the literature and put the practical implementation of the software results into a scientific context. 


\section{Level of Knowledge of Sustainable Development in Sustainable Building Information Management}

Another way of improving SD knowledge in the engineering education would be to aim for more SD product developments to make SD a more hands-on task that can also be evaluated from a SD perspective (Boks \& Diehl, 2006). However, the master's program Sustainable Building Information Management at University of Jönköping also contains such a course, which the students take parallel with Sustainability, Analyses and Simulations. Consequently, future research could benefit from including other courses that also contain SD in the program and evaluate if the level of knowledge of SD in general has increased when the students graduate from the master's program.

\section{Funding}

This research did not receive any specific grant from funding agencies in the public, commercial, or not-for-profit sectors.

\section{Competing Interests}

The author declares no conflict of interest.

\section{References}

Awadh, O. (2017). Sustainability and green building rating systems: LEED, BREEAM, GSAS and Estidama critical analysis. Journal of Building Engineering, 11, 25-29. doi:10.1016/j.jobe.2017.03.010

Azapagic, A., Perdan, S., \& Shallcross, D. (2005). How much do engineering students know about sustainable development? The findings of an international survey and possible implications for the engineering curriculum. International Journal of Phytoremediation, 30(1), 1-19. doi:10.1080/03043790512331313804

Baillie, C., Bowden, J. A., \& Meyer, J. H. F. (2013). Threshold capabilities: Threshold concepts and knowledge capability linked through variation theory. Higher Education, 65(2), 227-246. doi:10.1007/s10734-012-9540-5

Biggs, J., \& Tang, C. (2011). Teaching for quality learning at University. What the student does. (4th edition ed.). Berkshire, UK: Society for research into higher education and open university press. The McGraw-Hill companies.

Boks, C., \& Diehl, J. C. (2006). Integration of sustainability in regular courses: experiences in industrial design engineering. Journal of Cleaner Production, 14(9-11), 932-939. doi:10.1016/j.jclepro.2005.11.038

Bologna Working Group on Qualifications Framework. (2005). The framework of qualifications for the European Higher Education Area. . Retrieved from http:/ / ecahe.eu/w/images/7/76/A_Framework_for_Qualifications_for_the_Euro pean_Higher_Education_Area.pdf

Brundtland, G. H. (1987). Our Common Future (Report of the World Commission on Environment and Development). Oslo.

Carew, A. L., \& Mitchell, C. A. (2002). Characterizing undergraduate engineering students' understanding of sustainability. European Journal of Engineering Education, 27(4), 349361. doi:10.1080/03043790210166657

Chong, H. Y., Lee, C. Y., \& Wang, X. (2017). A mixed review of the adoption of Building Information Modelling (BIM) for sustainability. Journal of Cleaner Production, 142, 4114-4126. doi:10.1016/j.jclepro.2016.09.222 


\section{Level of Knowledge of Sustainable Development in Sustainable Building Information Management}

Doan, D. T., Ghaffarianhoseini, A., Naismith, N., Zhang, T., Ghaffarianhoseini, A., \& Tookey, J. (2017). A critical comparison of green building rating systems. Building and Environment, 123, 243-260. doi:10.1016/j.buildenv.2017.07.007

Entwistle, N. (2005). Contrasting perspectives on learning. In F. Marton, D. Hounsell, \& N. Entwistle (Eds.), The Experience of Learning: Implications for teaching and studying in higher education. 3rd (Internet) edition. (pp. 3-22). Edinburgh: University of Edinburgh, Centre for Teaching, Learning and Assessment.

Guldager Jensen, K., \& Birgisdottir, H. (2018). Guide to Sustainable Building Certifications. Danish Building Research Institute and 3XN Architects - GXN.

Jrade, A., \& Jalaei, F. (2013). Integrating building information modelling with sustainability to design building projects at the conceptual stage. Building Simulation, 6(4), 429-444. doi:10.1007/s12273-013-0120-0

Kabo, J., \& Baillie, C. (2009). Seeing through the lens of social justice: A threshold for engineering. European Journal of Engineering Education, 34(4), 317-325. doi:10.1080/03043790902987410

Lu, Y., Wu, Z., Chang, R., \& Li, Y. (2017). Building Information Modeling (BIM) for green buildings: A critical review and future directions. Automation in Construction, 83, 134148. doi:10.1016/j.autcon.2017.08.024

Maltese, S., Tagliabue, L. C., Cecconi, F. R., Pasini, D., Manfren, M., \& Ciribini, A. L. C. (2017). Sustainability Assessment through Green BIM for Environmental, Social and Economic Efficiency. Paper presented at the International High-Performance Built Environment Conference - A Sustainable Built Environment Conference 2016 Series SBE16, iHBE 2016.

Marjaba, G. E., \& Chidiac, S. E. (2016). Sustainability and resiliency metrics for buildings Critical review. Building and Environment, 101, 116-125. doi:10.1016/j.buildenv.2016.03.002

Meyer, J., \& Land, R. (2003). Treshold concepts and troublesome knowledge: linkages to ways of thinking and practising within the disciplines. Retrieved from Enhancing teaching-learning environments in undergraduate courses, occasional report 4:

Oduyemi, O., \& Okoroh, M. (2016). Building performance modelling for sustainable building design. International Journal of Sustainable Built Environment, 5(2), 461-469. doi:10.1016/j.ijsbe.2016.05.004

Segalàs, J., Ferrer-Balas, D., \& Mulder, K. F. (2010). What do engineering students learn in sustainability courses? The effect of the pedagogical approach. Journal of Cleaner Production, 18(3), 275-284. doi:10.1016/j.jclepro.2009.09.012

Segalàs, J., Ferrer-Balas, D., Svanström, M., Lundqvist, U., \& Mulder, K. F. (2009). What has to be learnt for sustainability? A comparison of bachelor engineering education competences at three European universities. Sustainability Science, 4(1), 17. doi:10.1007/s11625-009-0068-2

Suzer, O. (2015). A comparative review of environmental concern prioritization: LEED vs other major certification systems. Journal of Environmental Management, 154, 266-283. doi:10.1016/j.jenvman.2015.02.029

Wong, J. K. W., \& Zhou, J. (2015). Enhancing environmental sustainability over building life cycles through green BIM: A review. Automation in Construction, 57, 156-165. doi:10.1016/j.autcon.2015.06.003 